Watson, William J.-Report of a Series of Cases of Mastoiditis, with Operations. "Journal of Eye, Ear, and Throat Diseases,' May and June, 1901.

This paper consists of short reports of fifteen cases operated on at the Presbyterian Eye, Ear, and Throat Hospital, Baltimore, during the years 1898 and 1900 . Those operated on in 1899 have already been recorded in the Maryland Medical Journal, October, 1900. The cases are shortly reported in the order in which they occurred, not classified in any way; the conditions as to hearing-power, etc., before and after operation are given in some cases but not in others. In short, the majority of the reports are too incomplete to be of much value.

One case, male, aged seventeen, with discharge from left ear off and on for fifteen years, had much pain, but no tenderness over the mastoid, and a painful fluctuating swelling in the neck. On opening the mastoid, the tip was found to be perforated, and pus extended thence down the neck. The necrosed bone was cleared away, and the neck opened almost to the clavicle. Recovery uneventful. Another case with thrombosis of the lateral sinus ended fatally. The thrombus was cleared out till the blood-stream was restored. The clot was found to contain a focus of pus. The symptoms on admission were severe pain in the head, and some tenderness over the left mastoid; temperature 102 . No optic neuritis. Arthur J. Hutchison.

\title{
THYROID, Etc.
}

Packard and Hand.- "American Journal of the Medical Sciences," September, 1901.

An interesting case of sporadic cretinism is reported occurring in a child of six, who manifested continuous improvement under thyroid therapy for the two years during which he remained under the author's observation. On several occasions it was necessary to diminish the dose of thyroid owing to the indications of the therapeutic limit (weakness and rapid pulse). The marked improvement brought about in the case is shown by numerous illustrations accompanying the article.

\section{REVIEW.}

Atlas der Nasenkranklieiten. Enthaltend 356 Figuren in 475 Einzelbildern, auf 38 Tafeln. Von Hofrath Dr. Robert Krieg. Lieferungen fünfte, sechste und siebente. Mit Deutschem und Englischem Texte by Aцphonse Roman, Med. Kiel., M.R.C.S. Eng., L.R.C.P. Lond. Stuttgart: Ferd. Enke; Glasgow : F. Bandmeister. Price 6s. per Lieferung. 1901.

The three last parts of Dr. Krieg's already well-known atlas are chiefly devoted to those nasal and naso-pharyngeal conditions due to the ravages of syphilis and tuberculosis, and, as such, need but little comment, though the rare conditions depicted are of most value in a 
museum. Yet they are, generally speaking, well up to the height of excellence possessed by the earlier numbers. In these parts Dr. Krieg presents to the reader seventeen plates, the first being devoted to perforating ulcer of the septum, a condition which he considers to be nearly allied to perforating ulcer of the foot. In Fig. 23 he shows various conditions giving rise to this trouble, drawing attention to the fact, frequently overlooked, that rhinitis sicca is usually found in these patients, and that habitual epistaxis may be considered, as it were, a symptom of this disease, and that the "bleeding polypi of the septum" (Plate 24) are most probably a further development of the foregoing condition. At the end of his description of the plate he makes the following classification :

Metaplasia of the epithelium.

Proliferation of the epithelium (pachyderma).

Epistaxis (xanthosis).

Erosion.

Atrophy; cicatriza- Ulceration; pro- Proliferation of tissue; tion. liferation of the bleeding polypus. septum.

Plates 25 to 28 are devoted to tuberculosis of the nose, in which Dr. Krieg includes lupoid conditions, though, for our part, we are not inclined to consider lupus as an exhibition of tuberculosis. The most valuable of these plates is No. 28 , which shows some admirable examples of that rare condition, tuberculomata of the septum. The remaining plates, with the exception of Plate 38 , are devoted to syphilis and malignant disease. Dr. Krieg's drawings of the various syphilitic affections of the nose are most admirable and complete. The same may be said of his plates illustrating malignant disease. Plate 38 is devoted to various illustrations connected with accessory sinus disease; those showing the situation in which pus is found in suppuration of the various sinuses will be found extremely useful to teachers of rhinology. As we stated in our review of the earlier parts of this valuable atlas, we cannot overestimate the important part it will take in the diffusion of rhinological knowledge; and Dr. Krieg has performed a difficult task in a most satisfactory and complete way, and we congratulate him on his performance, and feel assured that his book will command a wide popularity.

R. Lake.

\section{BOOKS RECEIVED.}

E. B. Gleason, M.D.-Essentials of Diseases of the Nose and Throat. London: Henry Kimpton, 1901.

A. Logan Turner, M.D., F.R.C.S. (Edin.).-The Accessory Sinuses of the Nose; their Surgical Anatomy and the Diagnosis and Treatment of their Inflammatory Affections. Edinburgh: William Green and Sons, 1901.

J. Price-Brown, M.B.-Diseases of the Nose and Throat. London: Henry Kimpton, 1901. 